\title{
MULTI-FREQUENCY POLARIMETRIC SAR SIGNATURES OF LEAD SEA ICE AND OIL SPILLS
}

\author{
A.M. Johansson*, C. Brekke \\ UiT The Arctic University of Norway \\ Department of Physics and Technology \\ NO-9037, Troms $\varnothing$, Norway
}

\author{
G. Spreen, ${ }^{\dagger}$ \\ University of Bremen \\ Institute of Environmental Physics \\ D-28359 Bremen, Germany
}

\begin{abstract}
Synthetic aperture radar is used to identify and monitor oil spills. Separation from oil spill look-alikes is an important part of a fully automatic oil spill detection scheme. Here we investigate the polarimetric signatures for oil spills and newly formed sea ice (a well-known look-alike) in fully polarimetric Radarsat-2 satellite scenes. Using the fully polarimetric scenes we calculate four different parameters, co-polarization ratio, polarization difference, scattering entropy, and mean alpha angle. Three pairs of satellite scenes with comparable incidence angles are used. We observe that a combination of the co-polarization ratio and the polarization difference enables us to delineate the spills from their surrounding and also to discriminate the oil spills from the newly formed sea ice. The scattering entropy and the alpha values provide additional information about the scattering mechanisms of sea ice and oil spills.
\end{abstract}

Index Terms - SAR, polarimetry, Radarsat-2, oil spill, sea ice

\section{INTRODUCTION}

Marine oil spills are an important environmental problem and early identification, characterisation, and continuous monitoring of the spills are necessary. For this synthetic aperture radar (SAR) scenes are favoured as they are not hindered by clouds and can therefore be used for continuous ocean surface surveillance. Accurate identification of oil spills implies that oil spills needs to be separated from oil spill look-alikes. The latter includes other dark ocean surface features and known look-alikes are, e.g., low wind areas, newly formed sea ice and algae blooms (see e.g., $[1,2]$ and references therein). The example of young sea ice, is a year-round problem in the polar regions while algae blooms are a problem in, e.g., the Baltic Sea during the summer season. Polarimetric information in

${ }^{*}$ Thanks to the Norwegian Research Council for funding (Project number 237906).

$\dagger$ Thanks to the Institutional Strategy of the University of Bremen, funded by the German Excellence Initiative.
SAR scenes depends on, e.g. the dielectric constant, something that is expected to be lower for oil than for newly formed sea ice. In order to separate the oil spills from the look-alikes it is important to first establish which polarimetric features can separate them in SAR scenes. C-band SAR has traditionally been used for oil spill monitoring [3] as well as in sea ice monitoring [4]. Here we present initial results from a comparison of some multi-polarization features in C-band SAR for oil spills and newly formed sea ice at comparable incidence angles. For a future extended paper, we will expand this study towards inclusion of algae blooms as well as utilising different SAR frequencies.

\section{METHOD}

Using fully polarimetric Radarsat- 2 satellite scenes we extract information about four different polarimetric parameters; the co-polarization ratio $\left(\gamma_{c o}\right)$, scattering entropy $(\mathrm{H})$, mean alpha $(\alpha)$, and polarization difference (PD). The first three parameters have previously been used to monitor both oil spills and thin ice, see, e.g., $[3,4,5]$, and therefore extensive knowledge about the variation for these parameters under different conditions have been accumulated. However, limited data including both oil spill and newly formed sea ice exists. Here we compare the polarimetric signals for both oil spills and newly formed sea ice from three pairs of comparable satellite images comprising three different incidence angles. PD was shown in [3] to be a useful parameter for oil spill detection though it has not traditionally been used for newly formed sea ice detection in SAR images.

For consistency, all satellite scenes were processed in a similar manner as follows:

1. The scenes were radiometrically calibrated to complex backscatter values using the included metadata calibration information.

2. The scenes were spatially multi-looked [see, e.g. [6], page 29] resulting in a ground square pixel size of approximately $40 \mathrm{~m} \times 40 \mathrm{~m}$. 
3. Finally the scenes are geo-referenced to the National Snow and Ice Data Center Polar Stereographic Projection (https://nsidc.org/data/polar-stereo/ps_grids.html).

The multi-looking is a way to average a set of adjoining pixels in order to reduce the speckle (noise like inherent SAR property) within each scene. As the individual SAR scenes have different ground resolution they were multi-looked using different number of looks (see Tab. 1).

$\gamma_{c o}$ is calculated as;

$$
\gamma_{c o}=10 \times \log _{10}\left(\frac{\sigma_{V V}^{0}}{\sigma_{H H}^{0}}\right) .
$$

where $\sigma_{V V}^{0}$ is the backscatter values measured in the VV channel and $\sigma_{H H}^{0}$ is the backscatter values measured in the $\mathrm{HH}$ channel.

$H$ is calculated as;

$$
H=-\sum_{i=1}^{d} p_{i} \log _{d} p_{i},
$$

where $\mathrm{d}$ is the polarimetric dimension, $p_{i}=\lambda_{i} /\left(\lambda_{1}+\lambda_{2}+\lambda_{3}\right)$ and $\lambda_{i}$ are the eigenvalues, when reciprocity $(H V=V H)$ is assumed. The scattering entropy is one part of the $\mathrm{H} / \alpha$ decomposition [8].

$\alpha$ is calculated as;

$$
\alpha=\sum_{i=1}^{d} p_{i} \alpha_{i}
$$

where $\alpha_{i}$ is the alpha angle for the eigenvalues.

PD is calculated as;

$$
P D=\sigma_{V V}^{0}-\sigma_{H H}^{0}
$$

Note that in this instance $\sigma_{V V}^{0}$ and $\sigma_{H H}^{0}$ are given in linear units and hence PD is defined on a linear scale. PD is used in [7] to remove the adative noise and therefore enhance nearsurface wind variability and presence of oil spills in open water. This was also observed in, e.g., [3].

\section{EXPERIMENT}

In this study we use six Radarsat-2 Fine Quad-Pol (Radarsat2) scenes, where three of the scenes contain oil spills and three contain newly formed sea ice. The data is arranged in pairs of scenes, including one scene with oil spills and one scene with newly formed sea ice, roughly corresponding to three different incidence angles $(\theta), 30^{\circ}, 35^{\circ}$ and $47^{\circ}$ (Tab. 1).

All oil spill scenes contain an emulsion spill and in addition the scene with $\theta=35^{\circ}$ contain one plant oil spill and one crude oil spill (Fig. 1 top row). The oil spills are a part of the Norwegian Clean Seas Association for Operating Companies annual oil-on-water exercises in 2011 and 2012. For further information about the two experimental set-ups as well as weather observations see [3].
The Radarsat-2 scenes are collected with a swath width of $25 \mathrm{~km}$ and with an average resolution of $5.2 \mathrm{~m}$ (range - $\mathrm{rg}$ ) and $7.6 \mathrm{~m}$ (azimuth - az). In Tab. 1 the incidence angle and the noise floor (Noise Equivalent Sigma Nought (NESZ)) for the scenes are presented. The NESZ values at middle swath are calculated using specified meta data information that accompanies each individual scene and are beam specific.

Wind speed observations around the time of the SAR scenes were conducted for both the oil spill and newly formed sea ice cases and are presented in Tab. 1. For the oil spill scenes the wind speed data are taken from the ships participating in the exercise. For the newly formed sea ice scenes wind speed data are taken from R/V Lance. The wind speeds are between $2 \mathrm{~m} / \mathrm{s}$ and $7 \mathrm{~m} / \mathrm{s}$.

In Fig. 1 the $\gamma_{c o}, H$ and $\alpha$ values for the oil spill and the newly formed sea ice scenes with an incidence angle close to $35^{\circ}$ is shown. The three oil spills in the top row of Fig. 1, are from the left a plant oil spill (not used here), an emulsion spill and a crude oil spill. The newly formed sea ice is the yellow areas seen in the $\gamma_{c o}$ figure (Fig. 1d). For the oils spills are all parameters distinctly different for the spills compared to the open water surrounding them. For the sea ice cases the $\gamma_{c o}$ values are distinctly different for the newly formed sea ice and the older surrounding ice (Fig. 1d) while the separation is not clear for the other two parameters in e) and f). It should be noted that the oil spills are compared to a relatively smooth sea, due to the low wind conditions, and the newly formed sea ice areas are compared to the surrounding older and thicker sea ice that has higher backscatter.

As can be seen the oil spill have higher $H$ and $\alpha$ values and lower $\gamma_{c o}$ values than the surrounding open water. The PD values (not shown) are also lower than for the surrounding water. The newly formed sea ice has overall higher $\gamma_{c o}$ and PD (not shown) values than the surrounding sea ice. The newly formed sea ice is not uniform but can consists of young sea ice with different age, thickness, and appearance, such as areas with an inclusion of frost flowers and small scale structures (see e.g. [9, 10]). Within the scenes used in this study such phenomenons were observed and these properties are well known to affect the SAR backscatter signature. As an example of this the two leads observed in the $\gamma_{c o}$ figure in Fig. 1d show different $H$ and $\alpha$ signatures.

In Tab. 2 the mean parameter values for the oil spills and the newly formed sea ice areas are presented. The mean values are calculated by taking a transect (seen as white lines in Fig. 1) across the scene and identifying the outer boundaries of the oil spills and the newly formed sea ice areas. For all oil spill scenes one value for an emulsion is presented, additionally for the scene with $\theta=35^{\circ}$, values for crude oil spill is also presented.

Comparing the mean $\sigma_{H H}^{0}$ values in Tab. 2 we observe that the values for the newly formed sea ice is higher than the values for the oil spills for the corresponding incidence angles. For all of the newly formed sea ice scenes the mean 
Table 1: Properties of the SAR satellite scenes used in this study for oil spills (Oil) and newly formed sea ice (NI). Wind speed at the time of the satellite image acquisitions are also presented. * were originally reported as a 2 on the Beaufort scale

\begin{tabular}{lcccccc}
\hline Type & Date & Time [UTC] & $\theta\left[^{\circ}\right]$ & NESZ [dB] & $\begin{array}{c}\text { Multi-look } \\
(\mathrm{rg} \mathrm{x} \mathrm{az})\end{array}$ & $\begin{array}{c}\text { Wind } \\
\text { speed [m/s] }\end{array}$ \\
\hline Oil & $2012-06-15$ & $06: 20$ & $30.3-32.0$ & -34.70 & $4 \times 7$ & 4 \\
NI & $2015-01-26$ & $13: 39$ & $28.1-29.8$ & -33.46 & $4 \times 8$ & 7 \\
\hline Oil & $2011-06-08$ & $17: 27$ & $34.5-36.1$ & -34.46 & $5 \times 8$ & $1.6-3.3^{*}$ \\
NI & $2015-03-20$ & $14: 33$ & $35.3-37.1$ & -32.46 & $4 \times 6$ & 7 \\
\hline Oil & $2011-06-08$ & $05: 59$ & $46.1-47.3$ & -32.47 & $6 \times 8$ & $1.6-3.3^{*}$ \\
NI & $2015-05-26$ & $16: 59$ & $48.4-49.5$ & -30.08 & $6 \times 7$ & 4 \\
\hline
\end{tabular}
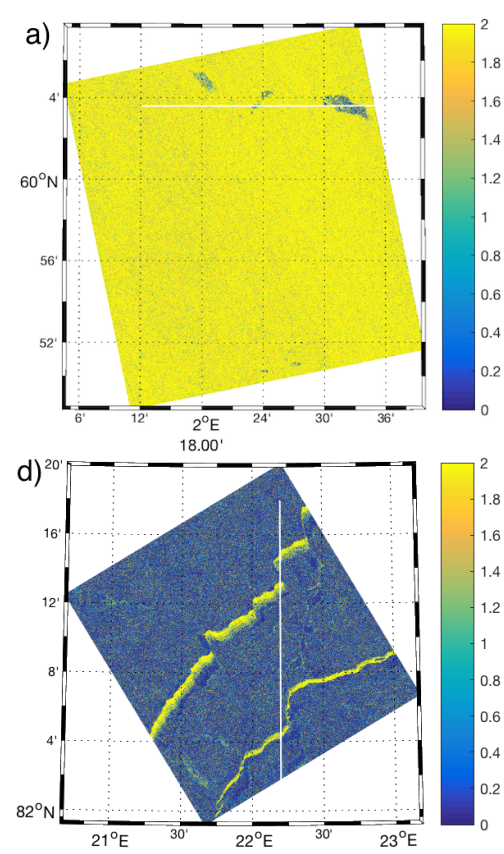

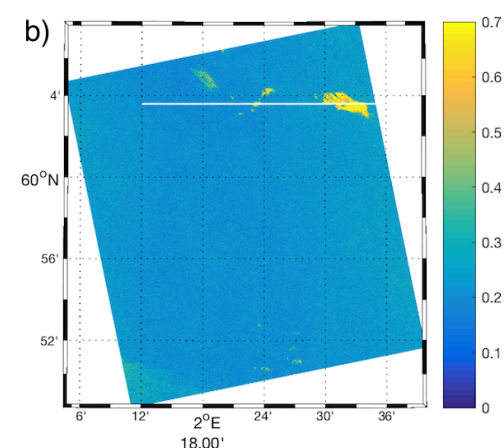

e)

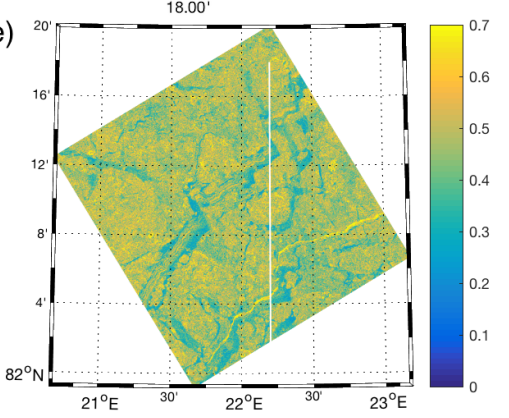

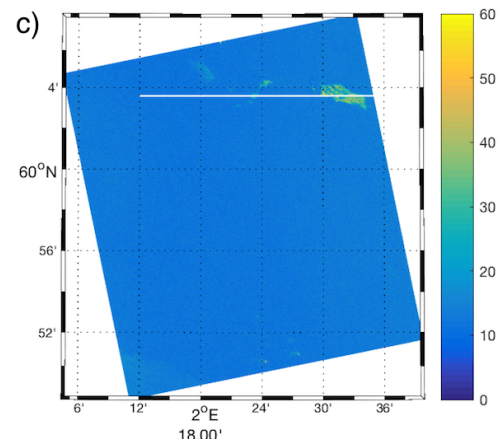

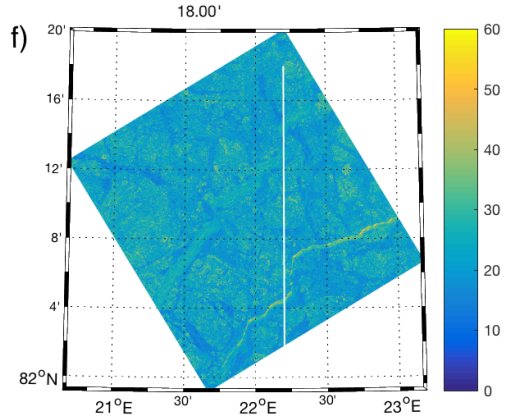

Fig. 1: Satellite backscatter parameter values for a)-c) oil spill and d)-f) newly formed sea ice. a) and d) shows $\gamma_{c o}$, b) and e) the scattering entropy, and c) and f) the $\alpha$ values. The satellite scenes used for a)-c) has $\theta=35^{\circ}$ and for d)-f) $\theta=36^{\circ}$. The white line indicate the transect lines used to identify areas used for the calculations for Tab. 2.

$\sigma_{H H}^{0}$ values are at least $8 \mathrm{~dB}$ higher than the corresponding NESZ (see Tab. 1). For oil spills and newly formed sea ice the highest incidence angle has the lowest $\sigma_{H H}^{0}$ value. The oil spill scene, given that it is only $2.2 \mathrm{~dB}$ above the NESZ, is likely affected by noise and this may affect the backscatter parameters presented here. The curved profile of the NESZ values with higher values at the near- and far range means that these pixels may be more affected by thermal noise than pixels on the same incidence angle value located at mid-range. Given how close the oil spill values are to the NESZ values for $\theta=47^{\circ}$ lower incidence angles may be preferable for oil spill detection and monitoring.

The $\alpha$ values are below $42.5^{\circ}$ and the $H$ values are below 0.9 and this indicate that we are within the surface scattering domain [8]. As the $H$ and $\alpha$ parameters also involves the cross-polarization parameters with even lower backscatter we may expect them to be more affected by the noise floor than the $\gamma_{c o}$ and PD values. Comparing the values presented in Tab. 2 we can see that for the lowest incidence angle scenes the $H$ and $\alpha$ values are lower for the newly formed sea ice compared to the oil spill. However, for the higher incidence angles the values are more comparable.

$\gamma_{c o}$ has been shown to be useful in separating oil spill and newly formed sea ice from the surroundings, see e.g. [1,9]. Within this study $\gamma_{c o}$ is shown to clearly separate these areas from the surrounding though the specific values are shown to vary between the scenes. For the oil spills the $\gamma_{c o}$ values are shown to increase with increasing incidence angle. The newly formed sea ice does not have the same trend though this likely could be related to different thickness of the newly 
Table 2: Backscatter parameter values $\sigma_{H H}^{0}, \gamma_{c o}, \mathrm{H}, \alpha$ and PD for oil spill (Oil) and newly formed sea ice (NI) areas. The * denotes the crude oil spill. $\theta$ is the mean incidence angle.

\begin{tabular}{ccccccc}
\hline$\theta\left[^{\circ}\right]$ & Type & $\begin{array}{c}\sigma_{H H}^{0} \\
{[\mathrm{~dB}]}\end{array}$ & $\begin{array}{c}\gamma_{c o} \\
{[\mathrm{~dB}]}\end{array}$ & $H$ & $\left.\alpha{ }^{\circ}\right]$ & $\mathrm{PD}$ \\
\hline 31 & Oil & -24.82 & 1.01 & 0.50 & 22.63 & 0.0014 \\
29 & NI & -14.64 & 0.18 & 0.25 & 13.91 & 0.0016 \\
\hline 35 & Oil & -24.45 & 1.42 & 0.44 & 20.78 & 0.0023 \\
& Oil $*$ & -26.17 & 1.13 & 0.58 & 27.72 & 0.0013 \\
36 & NI & -20.90 & 2.06 & 0.49 & 27.51 & 0.0047 \\
\hline 47 & Oil & -29.80 & 3.71 & 0.69 & 39.37 & 0.0019 \\
49 & NI & -22.22 & 1.90 & 0.63 & 34.37 & 0.0030 \\
\hline
\end{tabular}

formed sea ice as seen in [11]. In-situ observations indicate that the newly formed sea ice in the leads in the scene with the lowest incidence angle has a thickness of $0.20-0.25 \mathrm{~m}$ (Polona Itkin, Norwegian Polar Institute, personal communication, 2016) and that the sea ice within the two remaining scenes are thinner.

PD has been shown to be useful for oil spill detection (e.g. [3]) and in Tab. 2 we see that for the higher incidence angles there is a clear separation between the oil spills and the newly formed sea ice. Hence, indicating that this parameter is not only useful for the oil spill detection but it may be possible to use it to separate oil spill from sea ice look-alikes.

\section{CONCLUSIONS}

We observe that the oil spills studied here have a lower backscatter signature than the newly formed sea ice, for three compared incidence angles. Though the backscatter values will vary with sea ice thickness. The $H$ and $\alpha$ values are comparable between the oil spills and the newly formed sea ice areas, specifically at higher incidence angles. Though, the $\gamma_{c o}$ values can be used to separate the oil spill and look-alike from the surroundings and the polarization difference can be used at incidence angles $>35^{\circ}$ to separate the oil spill from the look-alikes. This may indicate that for accurate identification, monitoring, and characterisation of oil spills in ice infested waters multiple parameters are needed.

\section{ACKNOWLEDGMENTS}

Radarsat-2 data was provided by NSC/KSAT under the Norwegian-Canadian Radarsat agreement 2011, 2012 and 2015. This work has been supported by the Norwegian Polar Institutes Centre for Ice, Climate and Ecosystems (ICE) through the N-ICE project. The authors would like to thank NOFO for letting them participate in the exercises, and for providing in-situ information.

\section{REFERENCES}

[1] Brekke C., and Solberg, A.H.S., "Oil spill detection by satellite remote sensing”, Rem. Sens. Env., vol. 95, pp. 1$13,2005$.

[2] Konik, M., and Bradtke, K., "Object-oriented approach to oil spill detection using ENVISAT ASAR images", ISPRS J. Photogrammetry and Rem. Sens., vol. 118, pp. 37-52, 2016.

[3] Skrunes, S., Brekke, C., Eltoft, T., and Kudryavtsev V., "Comparing Near-Coincident C- and X-Band SAR Acquisitions of Marine Oil Spills", IEEE Trans. Geosci. Rem. Sens., vol. 45, no. 4, pp. 1958-1975, 2015.

[4] Geldsetzer, T., and Yackel, J. J., "Sea ice type and open water discrimination using dual co-polarized C-band SAR", Can. J. Remote Sens, vol. 35, no. 1, pp. 73-84, 2009.

[5] Johansson, A. M., King J. A., Doulgeris, A. P. Gerland, S., Singha, S., Spreen, G., and Busche, T., "Combined observations of Arctic sea ice with near-coincident colocated X-band, C-band, and L-band SAR satellite remote sensing and helicopter-borne measurements", J. Geophys. Res. Oceans, vol. 121, 2016.

[6] Oliver, C. and Quegan, S., "Understanding Synthetic Aperture Radar Images", SciTech Publishing Inc., Raleigh, USA, 2004.

[7] Kudryavtsev, V.N., Chapron, B., Myasoedov, A.G., Collard, F., and Johannessen, J.A., "On dual co-polarized SAR measurements of the ocean surface", IEEE Geosci. Remote Sens. Lett., vol. 10, no. 4, pp. 761-765, 2013.

[8] Cloude, S.R. and Pottier, E., "An entropy based classification scheme for land applications of polarimetric SAR", IEEE Trans. Geosci. Rem. Sens., vol. 35, no. 1, pp. 68-78, 1997.

[9] Brath, M., Kern, S., and Stammer, D., "Sea Ice Classification During Freeze-Up Conditions With Multifrequency Scatterometer Data", IEEE Trans. Geosci. Rem. Sens., vol. 51, no. 6, pp. 3336-3353, 2013.

[10] Isleifson, D., Galley, R.J., Barber, D.G., Landy, J.C., Komarov, A.S., and Shafai, L., "A Study on the CBand Polarimetric Scattering and Physical Characteristics of Frost Flowers on Experimental Sea Ice", IEEE Trans. GeoSci. Rem. Sens., vol. 52, no. 3, pp. 1787-1798, 2014.

[11] Nakamura, K., Wakabayashi, H., Naoki, K., Nishio, F., Moriyama, T., and Uratsuka, S., "Observation of Sea-Ice Thickness in the Sea of Okhotsk by Using Dual-Frequency and Fully Polarimetric Airborne SAR (Pi-SAR) Data", IEEE Trans. Geosci. Rem. Sens., vol. 43, no. 11, pp. 24602469, 2015. 